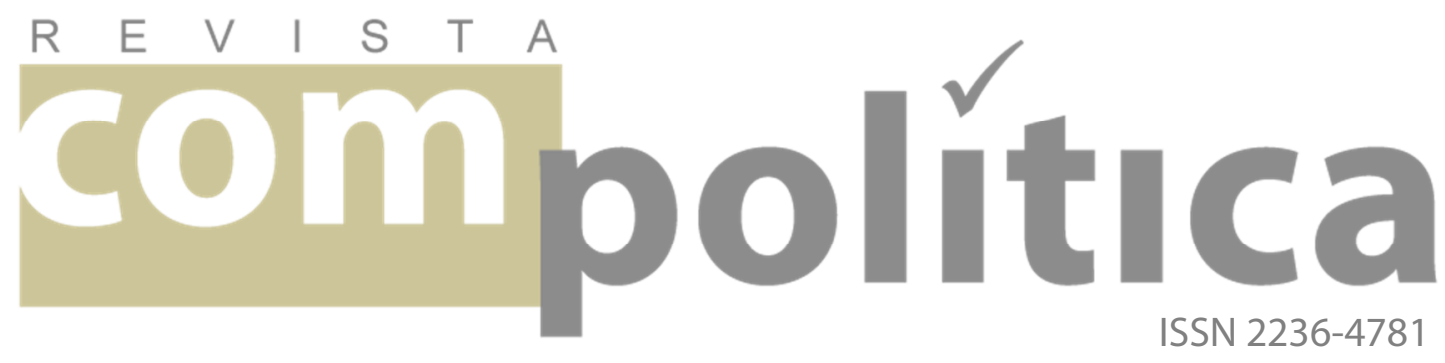

\title{
Comunicação Pública e Democracia: uma entrevista com João Pissarra Esteves
}

\section{[Public Communication and Democracy: an interview with João Pissarra Esteves]}

LUZ, Ana Javes

Jornalista, mestranda PPGCOM/UFRGS

[Journalist, master candidate from Communication Graduate Program at Rio Grande do Sul Federal University]

<anajaves@gmail.com>

\section{BECKER, Camila Lângaro}

Jornalista, mestranda PPGCOM/UFRGS

[Journalist, master candidate from Communication Graduate Program at Rio Grande do Sul Federal University]

<Becker.mila@gmail.com>

CARNIELLLI, Fiorenza Zandonade Jornalista e relações públicas, mestranda PPGCOM/UFRGS

[Journalist and PR, master candidate from

Communication Graduate Program at Rio Grande do Sul Federal University]

<fiorenzazc@vahoo.com.br>

Entrevista realizada em 30 de abril de 2015 pelos integrantes do Núcleo de Comunicação Política e Pública (Nucop), do Programa de Pós-Graduação em Comunicação e Informação da Universidade Federal do Rio Grande do Sul Universidade, o seminário "Comunicação Pública e Democracia", entre os dias 27 e 30 de abril de 2015 (PPGCOM/UFRGS). João Pissarra Esteves ministrou, nessa

GALINARI, Fabiana Carvalho

Jornalista, mestranda PPGCOM/UFRGS

[Journalist, master candidate from Communication

Graduate Program at Rio Grande do Sul Federal

University]

<bibiflores11@gmail.com>

\section{STEVENS, Leandro}

Doutor em Comunicação e Informação pela UFRGS

[PhD in Communication from Rio Grande do Sul

Federal University]

<leandrostevens@yahoo.com.br>

\section{GAUTIER, Tiago}

Mestre em Comunicação e Informação pela UFRGS [Master in Communications and Information from Rio Grande do Sul Federal University]

<tiagogautier@gmail.com>

[Interview conducted on April 30th 2015 by the members of Political and Public Communication Center (Nucop), from Communication and Information Graduate Program at Rio Grande do Sul Federal University (PPGCOM/UFRGS). João Pissarra Esteves taught, in this institution, the seminar class "Public Communication and Democracy", between April 27th and 30th 2015]

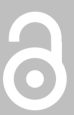

Revista Compolítica 5 (1), 2015 


\title{
Comunicação Pública e Democracia: uma entrevista com João Pissarra Esteves
}

\author{
LUZ, Ana Javes \\ BECKER, Camila Lângaro \\ CARNIELLI, Fiorenza Zandonade \\ GALINARI, Fabiana Carvalho \\ STEVENS, Leandro \\ GAUTIER, Tiago
}

$\mathrm{N}$ as sociedades democráticas, a comunicação pública exerce um papel fundamental. Constituída no espaço público, expressa uma dimensão ético-moral que se manifesta fática e normativamente, movida pelos princípios da publicidade, da crítica e do debate. Esta tem sido uma das reflexões fundamentais do professor João Pissarra Esteves. Doutor em Ciências da Comunicação, o professor da Faculdade de Ciências Sociais e Humanas da Universidade Nova de Lisboa tem uma expressiva produção teórica em torno dos conceitos de comunicação pública e espaço público, especialmente nas obras Sociologia da Comunicação (2011), A Ética da Comunicação e os Media Modernos (2007) e Espaço Público e Democracia (2003).

Nesta entrevista, Esteves fala sobre as relações entre comunicação pública e modelos deliberativos de democracia, as Novas Tecnologias de Informação e Comunicação (NTICs), princípios e limitações da comunicação pública nas sociedades contemporâneas e a importância do conceito não apenas para os processos políticos, mas, partindo de uma visão essencialmente sociológica, para a convivência e percepção do mundo comum. 
Qual a importância de estudar a comunicação pública para entender melhor, ou para poder aperfeiçoar, a democracia no modo como ela se apresenta na sociedade política contemporânea?

Para responder essa pergunta, tudo depende de um esclarecimento prévio do que nós próprios entendemos por democracia. Para algumas perspectivas, a comunicação pública será um aspecto acessório, portanto, não haverá grande cuidado relativamente a ela. $\mathrm{Eu}$ diria mesmo que talvez o funcionamento hoje em dia mais habitual das nossas sociedades não é muito atento, não é muito cuidadoso ao funcionamento e à qualidade da comunicação pública. No entanto, para outras perspectivas da democracia, ela é o elemento fundamental do funcionamento da vida democrática. Eu, pessoalmente, aproximo-me mais desse ponto de vista e, portanto, tendo a valorizar muito a comunicação pública e, consequentemente, a assumir uma atitude crítica relativamente àquilo que existe hoje.

Que tipo de democracia seria essa que tem a comunicação pública como fator fundamental? Como a comunicação pública consegue se tornar esse elemento?

Se quisermos simplificar a resposta recorrendo às terminologias mais ou menos consagradas, podemos dizer que essa concepção da democracia é o que normalmente se designa como uma democracia deliberativa. Exatamente à medida que a ideia fundamental dessa democracia valoriza muito a participação dos cidadãos, a participação cívica. É uma ideia de democracia que também não se circunscreve aos meros mecanismos formais da representação e dos processos de decisão, mas que tende a afirmar-se como aquilo que se 
costuma chamar uma forma de vida ou um estilo de vida. A democracia não propriamente como uma ocorrência esporádica, no momento das eleições, mas como uma prática de vida, de certo modo, cotidiana. 0 que dá, portanto, substância, é essa participação cívica. E o que, em última análise, possibilita que a democracia seja uma forma de vida mais ou menos cotidiana é precisamente o processo comunicacional. É a possibilidade de as pessoas, através da comunicação, terem alguma intervenção ao nível da sua vida política, quer do ponto de vista do conhecimento, da informação, do estarem informadas sobre aquilo que se passa, porém, talvez mais importante ainda do que isso, também utilizando a comunicação como um meio para poderem ter um papel de intervenção na própria vida política. Não é propriamente um modelo antagônico ou hostil aos mecanismos de representatividade, não é uma participação política que tenda ou que preconize substituir as competências de decisão, mas que propicie influenciá-las num determinado sentido. Portanto, nessa perspectiva, podemos dizer que é uma comunicação pública com uma dimensão performativa e pragmática forte, que não se limita propriamente à discussão dos assuntos, mas realiza essa discussão tendo uma certa perspectiva de intervenção política, de influenciar de algum modo a realidade social. Basicamente, é esse o modelo.

Em que tipo de prática o senhor observa que dá para perceber este tipo de democracia, este tipo de conversação? Quais seriam os desafios para que isso seja implementado de maneira mais abrangente nos processos políticos?

Há duas formas de nós nos referirmos a ele [ao modelo de democracia]. Normalmente nos referimos sempre em termos muito 
ideais, como qualquer coisa que não existe, que seria desejável que existisse, portanto num plano ideal, dos princípios, das expectativas, etc. Visto desse ponto de vista, pedir exemplos torna-se coisa um pouco complicada. Mas, a minha perspectiva não se restringe a essa interpretação meramente ideal, de algo modelo. Acho que o princípio deliberativo, de alguma forma, está inscrito na nossa matriz de democracia. Com certeza tem uma inscrição que é muito ideal, é muito dos princípios, é até da consagração em textos legais, dos princípios constitucionais que as leis fundamentais das democracias estabelecem. Mas há também algum vestígio ao nível das práticas. Há pouco eu referia-me às eleições, e referia-me até em um sentido um pouco pejorativo, um pouco como contraexemplo. Mas o processo eleitoral, em si, é um mecanismo deliberativo. É, de fato, uma oportunidade de as pessoas se pronunciarem. As próprias eleições podem ter diferentes formatos, diferentes figurinos. Em uma eleição em que não há grande esclarecimento público, quando as pessoas votam de uma forma mais ou menos aleatória, não vamos poder pensar muito em termos deliberativos. Contudo, podemos pensar algo diferente. Podemos pensar nas eleições como um momento em que, de fato, há um grande debate público, há um grande esclarecimento, há um grande envolvimento da sociedade. E, portanto, nesse caso, o resultado é um voto com peso, enquanto processo de formação da opinião. E já será um bom exemplo, nesse nível. Para todos os efeitos, convém sempre procurar exemplos para além daquilo que são os processos formais, porque se quisermos a ideia de algo mais evoluído em termos deliberativos, a par dos processos formais da democracia, neste caso, as eleições, há ainda outras oportunidades, outros espaços e outros mecanismos onde a intervenção dos cidadãos e os processos de influência poderão se realizar. É aquilo que normalmente se chama o espaço público e uma certa dinâmica do espaço público. Ou seja, acontece sempre que, em 
relação a qualquer assunto, se gera um movimento social, sempre que há uma intervenção da sociedade civil, até dos próprios partidos políticos, mas, preferencialmente para além destes (em organizações, associações, as próprias universidades, as igrejas, os diversos participantes; mesmo em termos individuais, seja da comunidade dos especialistas, seja do que for), sempre que haja um processo destes em que as questões políticas são objetos de escrutínio, são objetos de discussão, são objetos de um debate, e melhor ainda, se depois este debate tiver resultados, permitindo corrigir uma medida que manifestamente estava incorreta, não era justa, etc. Enfim, todos nós teremos recordações de exemplos, pequenos e grandes exemplos. Às vezes, a dimensão é muito pequena, na escala das cidades, por exemplo. Às vezes, em uma escala mundial. As questões relacionadas, por exemplo, às últimas grandes movimentações, em termos mundiais, como, p. ex., a segunda guerra no Iraque e as manifestações em todo o mundo, que não tiveram resultado imediato, não impediram a guerra, mas tiveram consequências políticas. Acho que essa descrição já é suficientemente precisa para perceber que, apesar de tudo, a democracia deliberativa é um campo muito vasto. Tudo aquilo que se traduza nesta operacionalidade, nesta virtualidade da comunicação pública, é enriquecedor deste ponto de vista da democracia e, portanto, deste caráter deliberativo da democracia.

Falando um pouco sobre essa ideia de modelo normativo da comunicação pública, muito baseado em uma troca de argumentação, em um modelo de racionalidade, como fica o lugar dos afetos, das paixões políticas, que sabemos que também estão envolvidos nos processos de decisão política? 
Claro, mas têm que estar. Isso é uma questão teórica controversa, que tem gerado polêmica. Eu posso exprimir a minha ideia sobre o assunto sem necessariamente fazer aqui uma discussão teórica muito densa. A minha perspectiva é esta: é absolutamente impossível pensar uma comunicação pública despida de afetos, porque isso é humano e faz parte da comunicação humana. [Mas] outra coisa é o papel que os afetos, a paixão, a emotividade, o papel que estes elementos têm na condução e na orientação da comunicação pública. E aí, sou mais racionalista. De um ponto de vista normativo, e até em função daquilo que expliquei antes, a comunicação pública é, de algum modo, um meio, um dispositivo através do qual a sociedade tende a construir certo entendimento e aponta para a formação de uma determinada opinião em nome da qual depois a influência pode ser exercida. Se isso não for conseguido, como dar efetividade à influência política? Ora, se aceitarmos este princípio, é muito difícil não valorizarmos a racionalidade. Não encontraremos outro meio para dirimir as diferenças, para fazer uma validação de argumentos, para que a decisão não seja aleatória. Vamos supor que andamos à procura da melhor opinião - não é de qualquer opinião; é daquela que, por qualquer circunstância, se impõe em um determinado momento - tudo isto me parece muito racional. Para todos os efeitos, é uma racionalidade que trabalha sobre e a par desses elementos da emotividade e que tem que saber viver com eles e até se aproveitar deles. Resumindo, contra as perspectivas mais radicalizadas, eu vejo uma diferença, mas não vejo uma oposição radical e considero que ambos fazem parte da comunicação pública.

Como o senhor avalia essa radicalidade no discurso político que está presente hoje, tanto na realidade brasileira quanto na realidade europeia - os fundamentalismos religiosos, os 


\section{partidos de extrema direita que vêm ganhando recentemente um espaço muito significativo, o que tem sido motivo de preocupação?}

Muito negativamente, sobretudo, em uma perspectiva democrática. Já nem falaria em uma democracia deliberativa, falaria muito genericamente em uma perspectiva democrática. Nós discutimos muito, podemos fazer um grande esforço para formalizar os princípios ou os critérios ou as práticas daquilo que é conhecido como uma estrutura da comunicação pública. Mas há pressupostos para que tudo isto funcione antes de termos uma comunicação pública fluida. É preciso que essa própria comunicação pública se registre num fundo social que também tenha suas regras. A tolerância é uma das regras fundamentais. Uma comunicação pública no sentido de que há muitas opiniões, muito debate, muita discussão, muito fervor, mas em que, à partida, não há qualquer expectativa, não há qualquer motivação fundamental para a criação de um entendimento, é um processo em que, do ponto de vista da comunicação pública (e do ponto de vista democrático), a formação da vontade está condenada. A comunicação pública supõe dos participantes certa disponibilidade para o entendimento, que as pessoas estejam disponíveis para escutar o argumento dos outros. Com certeza, todos se apresentam na perspectiva da convicção das suas opiniões e querem expô-las, mas não propriamente para impôlas, antes para convencer, para submetê-las a um escrutínio etc. 0 ambiente que você descreveu não é este. Eu nem quero discutir isto em termos de comunicação pública. Embora tendo, ou podendo ter, superficialmente, a aparência de uma comunicação pública, não é, de fato, comunicação pública porque, por sua própria natureza, é uma prática que nem sequer é compatível com o espírito democrático, não é uma prática normal do funcionamento das sociedades 
democráticas. Aliás, como sabemos, normalmente os discursos antidemocráticos aparecem, explícita ou implicitamente, associados a esse fervor. Muitas vezes não se discute a democracia, discutem-se outros problemas. São regimes de força, regimes de imposição e coisas desse gênero.

Não se pode falar nesses casos de uma comunicação pública porque ela necessita de alguns elementos e princípios que o senhor defende como fundamentais. Um deles é a racionalidade, ou seja, a necessidade de garantir o uso público da razão para a colocação dos argumentos, a disponibilidade de falar e ouvir. Outro seria a paridade argumentativa, isto é, a possibilidade das pessoas de estarem em iguais condições para a troca de argumentos. Em que base podemos imaginar a construção dessa igualdade de estatuto entre os participantes da comunicação pública, considerando todas as diferenças da sociedade?

Todos os princípios da comunicação pública são princípios ideais. E, nessa medida, qualquer juízo demasiado exigente quanto à sua verificação pode ser decepcionante, mesmo quando nós pensamos na universalidade da participação ou na abertura da discussão. Mas, indiscutivelmente, de todos os princípios, aquele em que esta dimensão ideal é mais forte - o que quer dizer também, em que sua concretização prática é mais difícil - é o princípio da paridade argumentativa, que é basicamente um princípio de igualdade dos estatutos dos participantes da comunicação pública. Por estas características, ele exige da nossa parte, enquanto estudiosos, enquanto investigadores, um maior cuidado, uma maior delicadeza na sua observação. Não na sua formulação, pois formulá-lo é muito fácil. Mas para perceber sua operacionalidade em termos empíricos. 
Eu diria que há indicadores, não tanto propriamente da sua concretização ou não concretização, mas da sua valorização ou não valorização. Por exemplo, uma situação concreta em que as regras do jogo são regras que tendem de alguma forma a suspender, a mitigar ou até, eventualmente, a corrigir aquilo que nós sabemos que são as diferenças estruturais que existem entre os sujeitos dentro da própria sociedade - porque temos as classes sociais, temos diferentes níveis de educação, de culturas, temos diferenças de diversos tipos. Portanto, se percebermos que, de algum modo, foi ali criada uma situação que tende a esbater, do ponto de vista comunicacional, essas diferenças (mesmo sem querer dizer que tais diferenças foram eliminadas). Há outras situações em que, provavelmente, é exatamente o contrário que se verifica: percebemos que a comunicação se torna uma espécie de prolongamento natural das diferenças já constituídas. É uma avaliação relativa, mas que é substancial porque, de um ponto de vista de prática social, de fato faz a diferença. Agora, se pensarmos isso já não tanto caso a caso, mas em termos de uma tendência, como estão, em geral, organizados os processos públicos? Quais são as regras? Como é o funcionamento da mídia? É mais em um sentido ou é mais noutro? [Se pensarmos em] Tudo que envolva comunicação pública, seja na escola, nos debates, nos diversos fóruns de discussão, nas universidades, na mídia, a própria forma como hoje se apresentam as novas tecnologias, a ocupação do espaço na internet, enfim, em todas as plataformas, o que é que a gente vê? Onde se percebe que há um esforço, uma disponibilidade, de algum modo, de todos para o entendimento? Isto não é muito estudado, isso tem a ver com o modo como as próprias pessoas olham umas às outras e se encaram em uma situação comunicacional. Portanto, temos estes ambientes comunicacionais onde se percebe que há uma tentativa para eliminar essas diferenças, ou não? Ou o que vemos é exatamente o contrário: cenários de 
comunicação que se tornam, muitas vezes, palcos de combate, palcos de guerra, onde parece que as diferenças são ainda mais exacerbadas? Eu considero que para discernir isto não tem uma receita. Do ponto de vista da investigação, isso requer uma boa dose de perspicácia do investigador. Sensibilidade do investigador. Essas não são coisas que possam ser propriamente aferidas, mensuradas, é muito no plano da interpretação, da perspicácia, do sujeito compreender os sinais.

Falando sobre essas diferenças entre os sujeitos e desse processo de confrontar argumentos, tende-se a ver as novas tecnologias como um espaço de diversidade, em que talvez esse debate possa acontecer. Esta seria a contribuição das NTICs?

Muito se tem escrito sobre isso. Do ponto de vista de um balanço dos resultados acadêmicos e científicos, acho que não podemos tirar grandes conclusões. Há perspectivas tão díspares e tão antagônicas! O que isso pelo menos significa é que não há condições para uma resposta incontroversa. Um pequeno contributo a título pessoal, mas também como resultado do envolvimento que tenho tido com o assunto enquanto investigador, eu sintetizaria a situação nesses termos, que não são muito esclarecedores, mas também acho que não consigo ir muito mais além disso: é verdade que há um conjunto de potencialidades muito significativas associadas às novas tecnologias, que justificam que olhemos para elas sob uma perspectiva positiva, mas que tardam em concretizar estes resultados. Antes, pelo contrário, a tendência da evolução das novas tecnologias, em aspectos muito importantes, não está a ir ao sentido de confirmar essas potencialidades, mas de negá-las na face da situação. Não está fácil. 


\section{Como o senhor entende essa rede de fluxos de comunicação, sob a perspectiva da comunicação pública, tendo em vista as novas tecnologias de comunicação? Como as NTICs podem contribuir para a formação dessa rede?}

Talvez, o primeiro aspecto (não sei se é o mais importante, mas é o primeiro), o mais evidente, é a possibilidade de alargamento, de extensão, por assim dizer, das redes de comunicação pública de um ponto de vista das mediações. A possibilidade de operacionalizar redes dinâmicas em contextos em que a mídia tradicional normalmente não permitia. Um segundo aspecto importante é a fluidez dessas redes. Fluidez aqui como a própria velocidade, a velocidade de circulação, a velocidade com que hoje se põe em movimento o discurso; é possível, portanto, operacionalizar troca de mensagens e esse tipo de coisas. Mas fluidez também do ponto de vista da intervenção dos diversos participantes na rede. Enquanto a mídia tradicional determinava posições relativamente fixas e rígidas no que diz respeito ao estatuto de cada um dos participantes, as redes hoje permitem movimentações muito mais rápidas, uma mobilidade muito maior de posições neste nível. E há ainda um terceiro aspecto, na organização da própria rede ou, neste caso, da rede enquanto conjunto de redes. Portanto, cada vez falamos mais de uma grande rede descentralizada e também se fala de uma estrutura rizomática, por oposição àquela ideia anterior de uma estrutura centralizada. E onde é que isso se joga? Joga-se depois, nos modelos comunicacionais. Nós tínhamos na mídia tradicional uma estrutura muito verticalizada, uma comunicação de poucos para muitos, uma comunicação de massa, um modelo tradicional com grandes centros de comunicação. Agora não, agora temos uma comunicação de muitos para muitos e isso tem vantagens. Também tem problemas 
mas, de um ponto de vista das potencialidades, tem inúmeras vantagens, traduz uma certa descentralização do poder. Enfim, esses são alguns tópicos que marcam imediatamente uma diferença muito grande das redes hoje daquilo que era o funcionamento tradicional da comunicação pública antes do aparecimento dessas novas tecnologias.

\section{Nos tensionamentos entre o público e o privado, as empresas privadas podem fazer essa comunicação pública, participar dessa rede? Como o senhor vê estes tensionamentos?}

As empresas podem fazer comunicação pública, como nós, enquanto sujeitos individuais, também podemos fazer comunicação pública. Quer dizer, comunicação pública está aberta a toda a sociedade, não há nenhum critério de exclusão no acesso à comunicação pública. 0 tensionamento não está propriamente na participação, o tensionamento pode estar na forma como nos apresentamos. Em termos abstratos, os problemas podem tanto se colocar em minha empresa, como podem se colocar em cada um de nós. Se eu apresentar uma situação qualquer de comunicação pública em que a única coisa que quero é impor a minha ideia, vou instrumentalizar todo o processo de forma simplesmente a influenciar os outros para fazer valer a minha ideia. Quer dizer, isso não é muito saudável. Isto é complicado, sobretudo, porque não é acidental. Hoje em dia, e vamos pôr isso da forma mais benigna possível, tendo em conta o valor simbólico da comunicação pública, a tentação para os diversos interesses particulares ou privados, também as empresas, de se apropriarem desse bem, é muito grande, porque eles podem daí tirar uma vantagem, porque é um bem que tem prestígio social. Exposto na forma mais elementar disso, eu consigo convencer amplamente 
uma sociedade de que o produto que eu fabrico, ou seja lá o que for, é o melhor, é o mais eficaz, é o mais bonito... E isso não é o resultado de uma discussão pública propriamente, mas de uma estratégia. Esses são os perigos. Mas, repito, não são só as empresas. Há perigos desse gênero em muitos outros níveis.

Então, pensando na comunicação como um lugar privilegiado, atualmente, para olhar o mundo, quais os desafios desse olhar? O que dar a ver, a partir desse ponto de vista da comunicação, pensando até nas responsabilidades do pesquisador da comunicação?

Vamos pensar no observatório. O observatório por excelência, no sentido de que faz parte, enquanto seres humanos, da nossa relação com o mundo. Uma componente reflexiva. Portanto, vamos acreditar que isso nos distingue enquanto espécie. Ao contrário das outras espécies, nós incorporamos uma relação reflexiva com o mundo. Nosso comportamento não é aleatório, não é meramente instintivo; incorpora aí uma certa racionalidade. Isso significa que nós observamos, fazemos uma análise e agimos em conformidade com um determinado objetivo. Portanto, isso, na mesma medida que faz parte da experiência de cada um enquanto indivíduo, está também incorporado nas diversas formas da nossa organização coletiva. Podemos observar coisas semelhantes a essa, por exemplo, numa empresa, numa organização e na própria sociedade em seu conjunto. Tudo isso para dizer que esse lugar de observação do mundo, quando pensamos nas nossas sociedades - não em todas as sociedades, mas nas sociedades democráticas onde vivemos - creio que é o espaço público, onde ocorre a comunicação pública, esse lugar de observação por excelência. É onde supostamente as nossas 
sociedades têm um lugar de observação sobre o mundo que nos permite esse juízo reflexivo quanto à melhor forma de enfrentar os problemas. A comunicação pública é aquilo que, em termos práticos, permite esse exercício da observação. É através da comunicação pública que nós partilhamos os acontecimentos, o que está a acontecer e aquilo que não está a acontecer, os relatos, as informações. É através da comunicação pública que nós debatemos a melhor resposta aos desafios. Foi detectado um problema, então, como nós iremos enfrentar esse desafio? Temos que nos pôr mais ou menos de acordo. Em uma sociedade democrática, não é suposto que qualquer um aja à sua maneira. É preciso uma resposta ordenada, disciplinada, etc. Portanto, nesse espaço da comunicação pública, chamado de espaço público, o que acontece assume uma função primordial desse ponto de vista. Ele dispõe dos meios e é o instrumento, o dispositivo por excelência, pelo qual essa observação pode ser garantida em nossas sociedades.

COMPOLITTICA ASSOCIACAAO BRASILEIRA DE PESQUISADORES EM COMUNICACÃO E POLIITICA

Diretoria da Associação/ Director Board

Presidente | President

Fernando Lattman-Weltman (UERJ)

Vice-Presidente | Vice-President

Arthur Ituassu (PUC-Rio

Secretária Executiva | Executive Secretary

Kelly Prudêncio (UFPR)

Corpo Editorial / Editorial Board

Editoras-Chefes: | Chief-Editors

Alessandra Aldé (UERJ) \& Maria Helena Weber (UFRGS)

Editores Executivos | Executive Editors

Fernanda Sanglard (UERJ), Rafael Cardoso Sampaio

(UFMG) \& Viktor Chagas (UFF)
A Revista Compolítica é uma revista eletrônica da Associação Brasileira de Pesquisadores em Comunicação e Política

[Revista Compolitica is an electronic journal published by the Brazilian Association of Political Communication Scholars]

Ao citar este artigo, utilize a seguinte referência bibliográfica

[To cite this article, please use the following reference]

LUZ, Ana Javes et al. Comunicação Pública e Democracia: uma entrevista com João Pissarra Esteves. In: Revista Compolítica $5(1), 2015$. 
